\title{
Review Article Norcantharidin, Derivative of Cantharidin, for Cancer Stem Cells
}

\author{
Chen-Hsi Hsieh, ${ }^{1,2,3}$ K. S. Clifford Chao, ${ }^{4}$ Hui-Fen Liao, ${ }^{3,5}$ and Yu-Jen Chen ${ }^{3,6}$ \\ ${ }^{1}$ Division of Radiation Oncology, Department of Radiology, Far Eastern Memorial Hospital, New Taipei City 220, Taiwan \\ ${ }^{2}$ Department of Medicine, School of Medicine, National Yang-Ming University, Taipei 112, Taiwan \\ ${ }^{3}$ Institute of Traditional Medicine, School of Medicine, National Yang-Ming University, Taipei 112, Taiwan \\ ${ }^{4}$ Department of Radiation Oncology, Columbia University, NY 10032, USA \\ ${ }^{5}$ Department of Biochemical Science and Technology, National Chiayi University, Chiayi 600, Taiwan \\ ${ }^{6}$ Department of Radiation Oncology and Department of Medical Research, Mackay Memorial Hospital, Taipei 104, Taiwan
}

Correspondence should be addressed to Hui-Fen Liao; liao.huifen@gmail.com and Yu-Jen Chen; chenmdphd@gmail.com

Received 31 March 2013; Revised 28 July 2013; Accepted 29 July 2013

Academic Editor: Myungsoo Joo

Copyright (c) 2013 Chen-Hsi Hsieh et al. This is an open access article distributed under the Creative Commons Attribution License, which permits unrestricted use, distribution, and reproduction in any medium, provided the original work is properly cited.

Cancer stem cells (CSCs) existing in human cancers have been demonstrated to be a major cause of cancer treatment resistance, invasion, metastasis, and relapse. Self-renewal pathways, Wnt/ $\beta$-catenin, Sonic hedgehog (Shh), and the Notch signaling pathway play critical roles in developing CSCs and lead to angiogenesis, migration, invasion, and metastasis. Multidrug resistance (MDR) is an unfavorable factor causing the failure of treatments against cancer cells. The most important and thoroughly studied mechanism involved in MDR is the active efflux of chemotherapeutic agents through membrane drug transporters. There is growing evidence that Norcantharidin (NCTD), a water-soluble synthetic small molecule derivative of naturally occurring cantharidin from the medicinal insect blister beetle (Mylabris phalerata Pallas), is capable of chemoprevention and tumor inhibition. We summarize investigations into the modulation of self-renewal pathways and MDR in CSCs by NCTD. This review may aid in further investigation of using NCTD to develop more effective strategies for cancer treatment to reduce resistance and recurrence.

\section{Introduction}

Cancer stem cells (CSCs) exist in many kinds of human cancers [1-5], and they are capable of continuous selfrenewal and differentiation $[6,7]$. In addition, CSCs may be responsible for tumor initiation, progression, metastasis, relapse, and resistance to chemotherapy or radiation therapy [8-11]. Several pathways, including Wnt $/ \beta$-catenin, Hedgehog, and Notch, have been identified as playing pivotal roles in CSC self-renewal [12-14], leading to relapse and multidrug resistance [15].

After developing resistance to a single drug or a class of drugs, cancer cells show cross-resistance to other functionally and structurally unrelated drugs, causing the failure of treatments against cancer cells [16]. This phenomenon is known as multidrug resistance (MDR). MDR has an unfavorable effect on successful outcomes of chemotherapy against cancer [17]. MDR can reduce intracellular drug accumulation by the active efflux of chemotherapeutic agents to modulate the expression of target genes controlling the cell cycle, cell adhesion, signal transduction, vascularization, and apoptosis.

Norcantharidin (NCTD, exo-7-oxabicylo-[2.2.1] heptane2,3-dicarboxylic anhydride), a water-soluble synthetic small molecule, is a demethylated analog of cantharidin (CTD, 7-oxabicyclo-[2.2.1] heptane-2,3-dicarboxylic acid) [18]. The molar weight, complexity, and heavy atom count for NCTD are $168.15 \mathrm{~g} / \mathrm{mol}, 246$, and 12 , respectively (Figure 1). CTD is a naturally occurring compound isolated from the medicinal insect blister beetle (Mylabris phalerata Pallas) [18]. The most important of the medicinal uses of CTD is its anticancer activities [18]. It is capable of inducing p53-dependent apoptosis and double-strand breakage of DNA in cancer cells [18-22]. CTD treatment could cause granulocytosis in vivo but not granulocytopenia induced by most chemotherapeutics [18]. This unique bioactivity renders CTD a promising lead compound for chemical modification to develop cancer therapeutics. However, the application of CTD is limited due to 


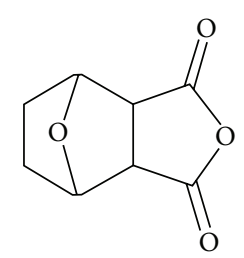

Norcantharidin (NCTD)

FIgURE 1: Chemical structure of norcantharidin (NCTD).

its toxicity to gastrointestinal and urinary tracts [23]. NCTD causes fewer nephrotoxic and inflammatory side effects than CTD [18, 23], and like CTD has been demonstrated as a potential agent against certain cancers [24]. The cytotoxic and antitumor activities of NCTD are multifarious: it can cause apoptosis, inhibition of angiogenesis, and metastasis for many cell lines, and it can affect multiple pathways controlling cell proliferation [25-27]. Moreover, NCTD was found able to inhibit P-glycoprotein (P-gp) [28] and overcome MDR [29].

NCTD decreased hepatic leukemia factor (HLF) protein levels, a gene implicated in hematopoietic stem cell (HSC) regulation, and induced apoptosis in the acute myeloid leukemia (AML) cell line MV4-11 by modulating the expression of several molecules that govern survival pathways, including HLF, SLUG, NFIL3, and c-myc, thereby inducing p53 and the mitochondrial caspase cascade that explores the ability of NCTD to target stem cells [30]. NCTD encapsulated liposomes modified with a novel murine anti-human CD19 monoclonal antibody 2E8 (2E8-NCTD-liposomes) could specifically target the B-lineage leukemia stem cells (B-LSCs) and their progeny in vitro [31]. Their results have shown that the internalization of 2E8-NCTD-liposomes into the cells and the subsequent release of NCTD into the cytoplasm to induce the apoptosis of $\mathrm{B}$ cells were responsible for specific cytotoxicity to the cells, using confocal microscopy and multiparameter flow cytometry analyses. In addition, immunoliposomes were able to induce the apoptosis of BLSCs via downregulating the HLF and upregulating the NFIL3 (nuclear factor, IL3 regulated) expressions at the mRNA level, proved by real-time RT-PCR [31].

Besides inhibiting cancer cells, NCTD also affects normal cells. NCTD inhibits peripheral blood mononuclear cell (PBMC) proliferation with a $50 \%$ inhibitory concentration (IC (50) $42.1 \pm 2.3$ microM without direct cytotoxicity or the arrest of cell-cycle progression in the cells [37]. NCTD modulates the differentiation and maturation of human myeloid DCs and causes deviation of standard DC differentiation toward a tolerogenic phenotype through calcineurin phosphatase inhibition and, thus, has potential for development as an immunosuppressant for transplant rejection [47]. NCTD is protective against renal tubulointerstitial fibrosis both in vivo and in vitro $[48,49]$. Epithelial-mesenchymal transition (EMT) contributes to the progression of renal tubulointerstitial fibrosis. NCTD antagonizes tubular EMT by inhibiting the TGF-betal/Smad pathway, which suggests that NCTD may play a critical role in preserving the normal epithelial phenotype and modulating tubular EMT [48].
On high glucose-induced extracellular matrix (ECM) and TGF-betal in human kidney proximal tubular epithelial (HK-2) cells, the antifibrogenic effect of NCTD on tubular interstitium in diabetic nephropathy $(\mathrm{DN})$ is independent of calcineurin $(\mathrm{CaN}) /$ Nuclear Factor of Activated T-cell (NFAT) pathway inhibition [49]. However, Yan et al. [50] also noted that NCTD has no effect on inactive lymphocytes but selectively acts on activated lymphocytes. These data support the multiple abilities of NCTD to influence cancer cells, CSCs, or normal cells.

In this paper we review the current understanding of NCTD, which has cancer treatment potential, with a focus on overcoming MDR and CSC self-renewal characteristics (Table 1).

\section{Self-Renewal Pathways of Cancer Stem Cells}

2.1. Wnt/ $\beta$-Catenin Pathway. The Wnt/ $\beta$-catenin pathway modulates cell proliferation, migration, apoptosis, differentiation, and stem cell self-renewal [51-53]. $\beta$-Catenin participates in two distinct functions in the cell. Membranelocalized $\beta$-catenin is a protein adhesive that with E-cadherin maintains cell-cell adhesion [54]. Cytoplasmic accumulation of $\beta$-catenin cooperates with the transcription factors $\mathrm{T}$ cell factor/lymphoid enhancer factor (TCF/LEF) as a transcription activator, which eventually leads to activation of Wnt target genes such as c-Jun, c-Myc, fibronectin, and cyclin D1 [55-60].

Increasing evidence supports the ability of NCTD to inhibit the Wnt/ $\beta$-catenin pathway. Cimmino et al. [32] reported that NCTD could impair the growth of medulloblastoma cells and promoted the loss of beta-catenin activation. Additionally, the Wnt/ $\beta$-catenin signaling pathway contributes to refractory and relapsed leukemia. Chuang et al. [33] also confirm NCTD as an inhibitor for the Wnt/ $\beta$ catenin pathway. They note that NCTD (50 microM) inhibits the proliferation of Jurkat cells with dominant beta-catenin signaling by $64 \%$ in a concentration-dependent manner. In CT26 colorectal adenocarcinoma cells, NCTD decreases the adhesive ability of CT26 cells and shows a downregulation of several cadherin-catenin adhesion molecules in vitro. It could reduce both the pulmonary metastatic capacity of CT26 cells and prolong the survival time of the tumor-bearing mice [34] (Figure 2).

NCTD also inhibits the activation of Wnt target genes such as c-Jun and cyclin D1. In human gallbladder carcinoma xenografted tumors, an NCTD-treated group decreased the expression of cyclin-D1, Bcl-2, and survivin proteins/mRNAs significantly [35]. Similar results were noted in human gallbladder carcinoma GBC-SD cells in vitro [36]. NCTD inhibits the growth of GBC-SD cells by increasing the rate of cell apoptosis and decreasing the expression of the proliferationrelated genes, such as cyclin-D1 or the apoptosis-related genes [36]. NCTD also arrests the cell-cycle progression from the G1 transition to the $\mathrm{S}$ phase through declining cyclin D3, E, A, and B transcripts and stops protein production in phytohemagglutinin (PHA-) treated peripheral blood mononuclear cells (PBMC) [37]. 


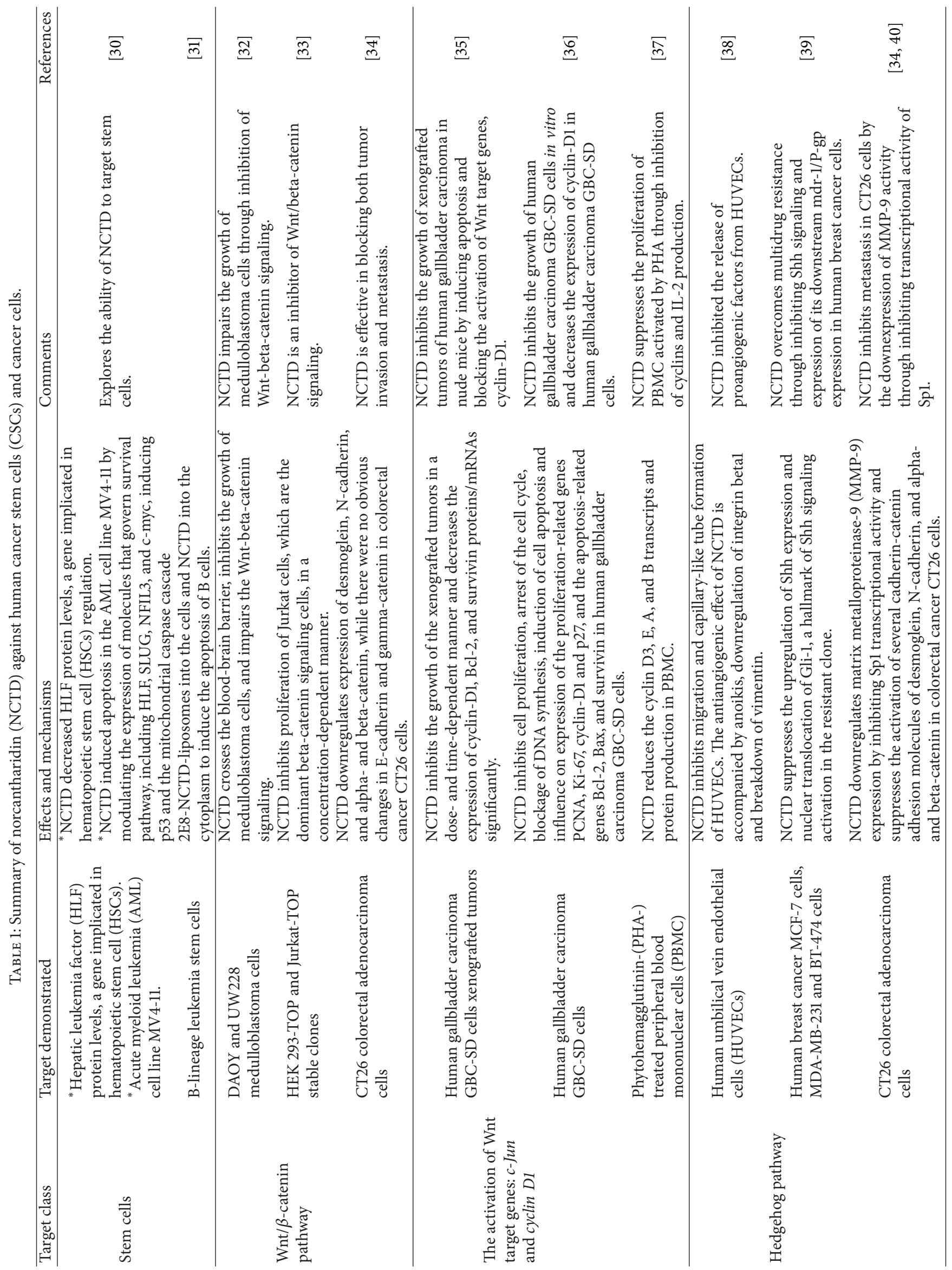




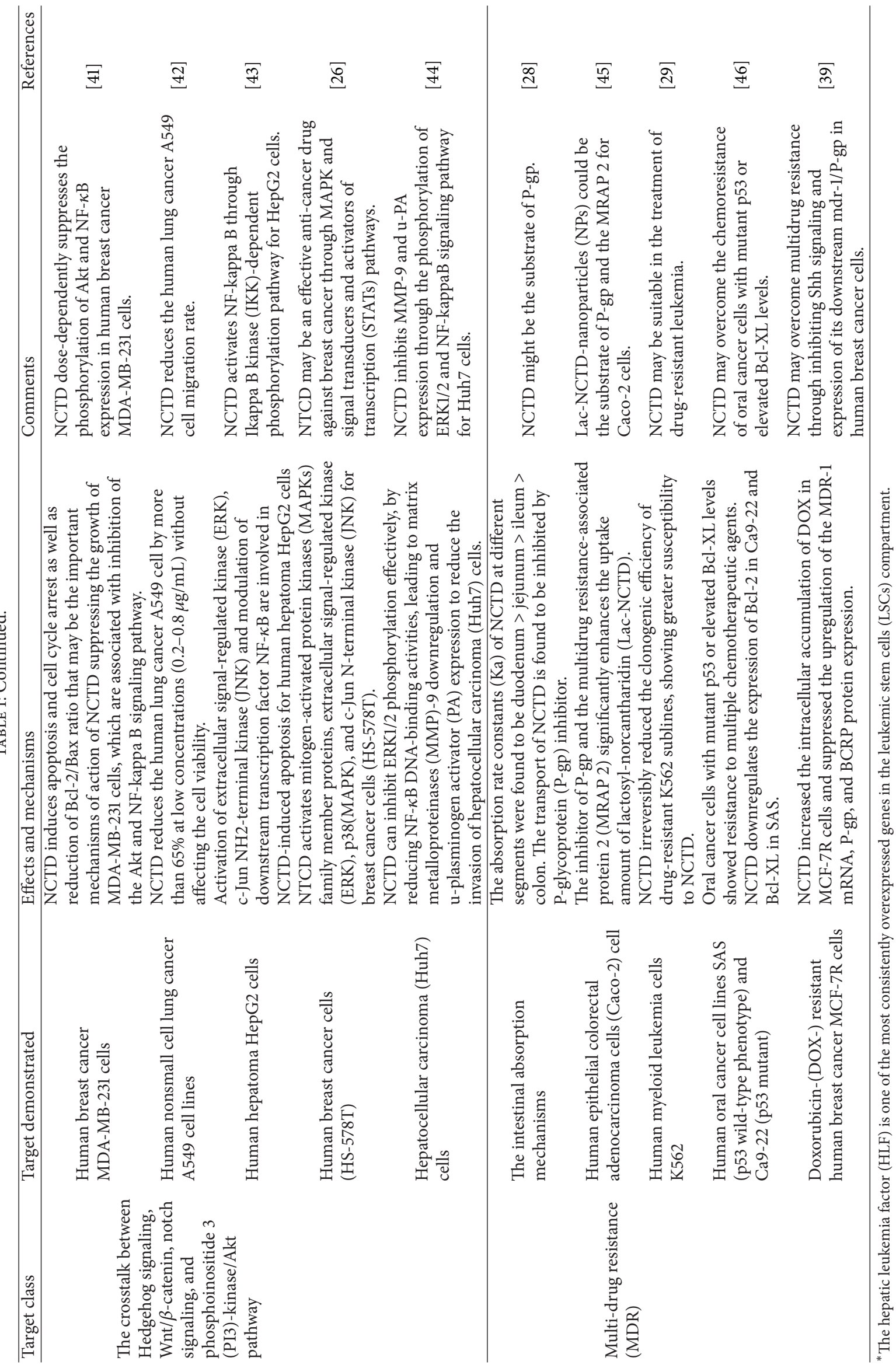




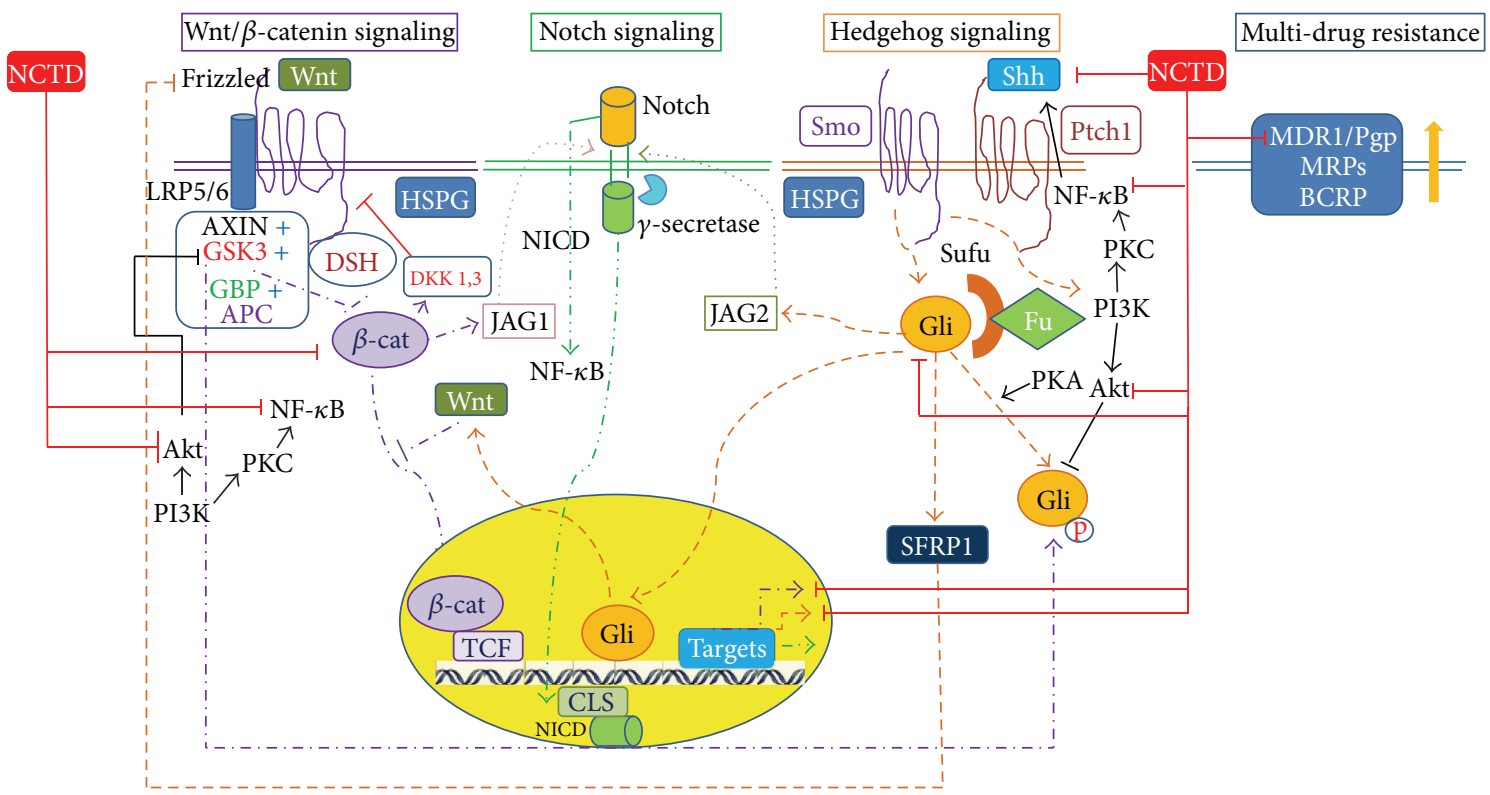

FIGURE 2: Model of crosstalk between hedgehog signaling, Wnt/ $\beta$-catenin signaling, notch signaling, and phosphoinositide 3 (PI3)kinase/Akt pathway and targeting by norcantharidin (NCTD). $\beta$-cat: $\beta$-catenin; BCRP: breast cancer resistance protein; Fu: fused; HSPG: Gli: glioma-associated oncogene family zinc finger; GSK-3: glycogen synthase kinase 3; Heparin-sulfated forms of proteoglycans; NICD: intracellular domain of Notch; JAG: Protein jagged; LRP: Low-density lipoprotein receptor-related protein; MDR: multidrug resistance; MRPs: multidrug resistance proteins; NCTD: norcantharidin; P-gp: P-glycoprotein; PI3K: phosphoinositide 3-kinase; PKA: protein kinase A; Ptch: patched; SFRPs: secreted frizzled receptor proteins; Shh: sonic hedgehog; Smo: smoothened; Sufu: suppressor of fu.

2.2. Hedgehog Pathway. The Hedgehog ( $\mathrm{Hh})$ signaling pathway plays a major role as regulator of cell differentiation, tissue polarity and cell proliferation $[61,62]$. There are three secreted proteins belonging to the Hh family, including Sonic Hedgehog (Shh), Desert hedgehog, and indian hedgehog. In the absence of hedgehog ligands, the transmembrane receptor Patched (Ptch) blocks the Smoothened (Smo) function [63-65]. If secreted hedgehog ligands bind to Ptch1, then Smo is reversed to activate the Shh signaling pathway, resulting in the translocation of the transcription factor Gli (glioma-associated oncogene family zinc finger) family into the nucleus to modulate the expression of target genes, such as cyclin D, cyclin E, Myc, and elements of the EGF pathway, which control the cell cycle, cell adhesion, signal transduction, vascularization, and apoptosis [63-67]. Hh plays a central role in the control of proliferation and differentiation of both embryonic stem cells and adult stem cells; the aberrant activation of Hh signaling could lead to the generation of CSCs and the development of cancer [68] or cancer angiogenesis, metastasis, and invasion [69].

The plasma VEGF levels of tumor-bearing mice, migration, and capillary-like tube formation of HUVECs are suppressed by NCTD with potential antimetastasis and antiangiogenesis [38]. Chen et al. [39] demonstrated that the Shh expression for various cell lines of breast cancer is suppressed by NCTD and the nuclear translocation of Gli-lis inhibited as well. NCTD inhibits metastasis in CT26 cells by the downexpression of matrix metalloproteinase-9 (MMP-9) activity and of several cadherin-catenin adhesion molecules [34] through inhibiting the transcriptional activity of Sp1 [40] (Figure 2).
2.3. The Crosstalk between Hedgehog Signaling, Wnt/ $\beta$-Catenin, Notch Signaling, and Phosphoinositide 3 (PI3)-Kinase/Akt Pathway. There are crosstalks between hedgehog signaling, Wnt/ $\beta$-catenin, notch signaling, and the phosphoinositide 3kinase (PI3-kinase)/Akt pathway. These signaling molecules are activated by G-protein-coupled receptors, such as Frizzled or Smo [70, 71]. The pathways prevent phosphorylationdependent proteolysis of key effectors, cubitus interruptus, or $\beta$-catenin [72]. The study notes that activation of Gli stimulates the transcription of Wnt ligands [64]. The molecule in Wnt signaling, glycogen synthase kinase (GSK)$3 \beta$, regulates the molecules involved in Hh signaling [73], but the pathological response to oncogenic $\mathrm{Hh}$ signaling is also dependent on canonical Wnt/ $\beta 3$-catenin signaling [74]. Taken together, it is apparent that crosstalk between Wnt and Hh signaling is evident.

The PI3-Kinase/Akt pathway links to the Wnt/ $\beta$-catenin pathway. The PI3-Kinase/Akt pathway acts as a survival signal and plays a key role in the regulation of apoptotic events. The PI3-Kinase/Akt pathway is important in regulating the mammary stem/progenitor cells by promoting $\beta$-catenin downstream through phosphorylation of GSK-3 $\beta$. Activated Akt was shown to be able to phosphorylate Ser9 on GSK$3 \beta$, which may decrease the activity of GSK-3 $\beta$, thereby stabilizing $\beta$-catenin $[75,76]$. Akt can exert its antiapoptotic effects in several different ways, such as negatively regulating proapoptotic factors and stimulating the nuclear factorkappaB (NF- $\kappa \mathrm{B})$ survival pathway [77]. NF- $\kappa \mathrm{B}$ can promote tumorigenesis and is linked to cell invasion and metastasis. The suppression of $\mathrm{NF}-\kappa \mathrm{B}$ activation is effective in the prevention and treatment of cancer [78]. 
More reports have demonstrated the direct or synergistic role of PI3-kinase/Akt activation in mediating the biological effects of hedgehog signaling [79-82]. Genetic studies in mice reveal that the insulin-like growth factor (IGF)-PI3kinase/Akt pathway provides a synergistic signal for Shh in tumor formation [83, 84]. Akt positively regulates Shh signaling by controlling protein kinase A-(PKA-) mediated Gli inactivation [79]. Shh induces capillary morphogenesis of endothelial cells through activation of c-Fes/PI3-kinase pathways [82] noted in the angiogenic study of bone-marrowderived endothelial progenitor cells (BM-EPC) [81]. Shh signaling could promote the metastasis of gastric cancer cells through the activation of the PI3K/Akt pathway, which may lead to epithelial mesenchymal transition and MMP-9 activation [85]. Shh may protect the astrocytes from oxidative stress by activating the PI3-Kinase/AKT pathway [86].

Likewise, the Shh pathway is linked to transcription factor $\mathrm{NF}-\kappa \mathrm{B}$ signaling. It has been suggested that overexpression of Shh is activated by NF- $\kappa$ B in pancreatic cancer and pancreatic cancer cell proliferation is accelerated by NF- $\kappa \mathrm{B}$ in part through Shh overexpression [87]. Kasperczyk et al. further characterized Shh as a novel NF- $\kappa \mathrm{B}$ target gene and mapped a minimal NF- $\kappa$ B consensus site to position +139 of the Shh promoter [88].

Notch signaling is known to control cell proliferation and apoptosis to modulate the development of many organs [89]. A number of recent studies have demonstrated that Notch-activated genes and pathways can drive tumor growth through the expansion of CSCs [89-94]. Notch 1, a transmembrane receptor, has been reported to crosstalk with the NF- $\kappa$ B pathway in diverse cellular situations [95-97]. Specifically, Notch-1 is necessary for the expression of several NF- $\kappa$ B subunits $[96,98]$, and it stimulates NF- $\kappa$ B promoter activity [96].

Activation of PI3K/Akt and NF- $\kappa$ B increases the migration of cancer cell lines such as human lung cancer A549 cells [99] and human breast cancer MDA-MB-231 cells [100]. NCTD dose-dependently suppresses the phosphorylation of Akt and NF- $\kappa \mathrm{B}$ expression in human breast cancer MDAMB-231 cells [41]. Moreover, NCTD reduces the human lung cancer A549 cell migration by more than $65 \%$ at low concentrations $(0.2-0.8 \mu \mathrm{g} / \mathrm{mL})$ without affecting cell viability [42]. Activation of extracellular signal-regulated kinase (ERK), c-Jun NH2-terminal kinase (JNK) and the modulation of downstream transcription factor NF-kB are involved in NCTD-induced apoptosis for human hepatoma HepG2 cells [43]. Similarly, NTCD is effective as a c-Jun Nterminal kinase inhibitor, SP600125, for breast cancer cells (HS-578T) [26]. NCTD can inhibit ERK1/2 phosphorylation effectively, by reducing NF- $\kappa$ B DNA-binding activities, leading to matrix metalloproteinases (MMP)-9 downregulation and $\mathrm{u}$-plasminogen activator (PA) expression to reduce the invasion of hepatocellular carcinoma (Huh7) cells [44]. It suggests that NCTD, not solely due to viability inhibition, may inhibit the PI3-K/Akt pathway to contribute activity against CSCs (Figure 2).

\section{Multidrug Resistance (MDR)}

Multidrug resistance (MDR) is an unfavorable factor causing the failure of treatments against cancer cells [16]. It occurs when cancer cells acquire simultaneous resistance to various kinds of chemotherapeutic agents with no structural or functional similarities [101]. Although many mechanisms of MDR in cancer cells have been studied, the most important and thoroughly studied mechanism involves the reduction in intracellular drug accumulation by the active efflux of chemotherapeutic agents through membrane drug transporters. These ATP-binding cassette $(\mathrm{ABC})$ proteins include p-glycoprotein (P-gp, MDR1, and ABCB1) [17, 102, 103], the multidrug resistance protein 1 (MRP1) $[104,105]$, lung resistance protein (LRP) [106, 107], and breast cancer resistance protein (BCRP, ABCG2) [108-111]. The P-gp acts as a drug efflux pump to extrude a wide range of different chemotherapeutic drugs out of MDR cancer cells [102].

NCTD is found to inhibit the P-gp [28] and the multidrug resistance-associated protein 2 (MRAP 2) to significantly enhance the uptake amount of nanoparticles with lactosylnorcantharidin in a heterogeneous human epithelial colorectal adenocarcinoma cells monolayer model [45]. NCTD irreversibly reduced the clonogenic efficiency of parental and drug-resistant K562 sublines, with drug-resistant sublines showing greater susceptibility to NCTD than parental cells. The data suggest that NCTD may be suitable in the treatment of drug-resistant leukemia [29]. Similarly, apoptosis of oral cancer cells with resistance to multiple chemotherapeutic agents can be induced by NCTD [46]. In a study of doxorubicin-(DOX-) resistant human breast cancer MCF7R cells, NCTD increased the intracellular accumulation of DOX in MCF-7R cells and suppressed the upregulation of the MDR-1 mRNA, P-gp and BCRP protein expression but not MRP-1 [39]. Collectively, it is apparent that NCTD might be the substrate of P-gp and might overcome multidrug resistance in cancer cells.

\section{Prospect of Using Norcantharidin against Cancer Stem Cells}

The experimental demonstration of CSCs in several human tumors in recent years promises a new cellular target for anticancer drug discovery $[1,4,5,112-114]$. Among various agents that target self-renewal pathways, small molecules that target the hedgehog pathways are in early clinical studies and have shown promising results $[115,116]$. The Smo antagonist cyclopamine was shown to lead to the rapid regression of basal cell carcinoma in patients [117]. In addition, an oral small molecule inhibitor of Smo, GDC-0449, has shown limited toxicity and partial responses in advanced basal cell carcinoma tumors in a Phase I clinical trial, and it is advancing to Phase II trials for metastatic colorectal cancer and other advanced epithelial tumors [118]. Given that the expression of $\mathrm{SHH}$ in various breast cancer cell clines and the nuclear translocation of Gli-1 are suppressed by NCTD [39], it may imply that NCTD can be used to target renewal signaling against CSCs. 
The Wnt/ $\beta$-catenin pathway initiates a signaling cascade critical in both normal development and the initiation and progression of cancer [119-121]. Various $\beta$-catenin/TCF inhibitors, most of them belonging to low molecular-weight inhibitors, downregulate the expression of $\beta$-catenin/TCFresponsive genes and disrupt the interaction of elementbinding protein (CBP) with $\beta$-catenin [122] or disrupt $\beta$ catenin/TCF complexes directly [123]. Similarly, NCTD can promote the loss of $\beta$-catenin activation [32] and inhibit the proliferation of Jurkat cells with dominant $\beta$-catenin signaling [33]. These data suggest that NCTD has significant therapeutic potential for the treatment of cancer with activated $\mathrm{Wnt} / \beta$-catenin pathways.

Epithelial cell adhesion molecule (EPCAM) is highly expressed in numerous solid tumors, and it has recently been shown to be expressed on tumor-initiating cells from breast, prostate, colon, and pancreatic cancer $[3,113,124]$. There are several antibodies against cell surface markers of tumor-initiating cells in clinical studies $[125,126]$. However, EPCAM-specific mAbs have shown a limited efficacy in clinical trials [125]. These data suggest that an immune response stimulated by these mAbs by itself might not be effective in killing EPCAM overexpressing tumor cells in clinical settings. To overcome the limitations of the naked antibodies, catumaxomab, a trifunctional antibody against EPCAM and $\mathrm{CD} 3$, brings cancer cells into proximity with the immune system cells that can destroy them [127]. NCTD is not only cytotoxic for cancer cells but also plays a role in modulating the development of dendritic cells to prolong skin allograft survival [47]. With the multiple roles of NCTD, it needs to be determined whether NCTD can modulate immune tolerance or antibody-dependent cellular cytotoxicity (ADCC) to kill EPCAM overexpressing tumor cells in a microenvironment.

Radiation sensitization is one of the important directions to develop anticancer agents for radiotherapy or chemoradiation therapy. Shh signaling has been discovered as a mechanism rendering cancer cells resistant to chemoradiation. In clinical practice, the expression of Ptch or Gli-1 has been significantly associated with a poor prognosis for oral cavity cancer patients [128]. Cancer cells at the G2/M phase are known to be sensitive to radiation $[129,130]$. NCTD could suppress the expression of Shh and Gli-lfor various cell breast cancer lines [39]. NCTD can significantly increase the proportion of cells in G2/M phase and decrease the proportion of cells in S phase for CT26 colorectal adenocarcinoma cells [27], gallbladder carcinoma GBC-SD cells [36], and human breast cancer MDA-MB-231 cell lines [41]. Taken together, NCTD may play a dual role as radiosensitizer and CSC toxic agent.

Safety issues are worth noting in efforts to develop chemotherapy-enhancing or radiation sensitization agents aimed at eliminating CSCs. Research efforts should be oriented toward avoiding, or at least minimizing, the inhibition of crucial mechanisms for normal stem cell maintenance.

NCTD has pharmacological potential in the treatment of CSCs. The beneficial effects of NCTD include the modulation of CSC self-renewal pathways, overcoming multidrug resistance and as radiation sensitizer. Although the mechanisms are not clearly addressed in the reviewed publications, the results indicate that further evaluation of NCTD is warranted. In particular, the mechanisms of action by which NCTD modulates CSC characteristics should be clarified. Preclinical studies to pave the way for clinical trials may eventually enable scientists to discover more effective strategies for cancer treatment to reduce resistance and recurrence and, eventually, to improve survival of cancer patients.

\section{Conflict of Interests}

The authors declare that they have no conflict of interests.

\section{References}

[1] D. Bonnet and J. E. Dick, "Human acute myeloid leukemia is organized as a hierarchy that originates from a primitive hematopoietic cell," Nature Medicine, vol. 3, no. 7, pp. 730-737, 1997.

[2] S. K. Singh, I. D. Clarke, M. Terasaki et al., "Identification of a cancer stem cell in human brain tumors," Cancer Research, vol. 63, no. 18, pp. 5821-5828, 2003.

[3] C. Li, D. G. Heidt, P. Dalerba et al., "Identification of pancreatic cancer stem cells," Cancer Research, vol. 67, no. 3, pp. 1030-1037, 2007.

[4] Z. F. Yang, D. W. Ho, M. N. Ng et al., "Significance of CD90 cancer stem cells in human liver cancer," Cancer Cell, vol. 13, no. 2, pp. 153-166, 2008.

[5] C. A. O'Brien, A. Pollett, S. Gallinger, and J. E. Dick, "A human colon cancer cell capable of initiating tumour growth in immunodeficient mice," Nature, vol. 445, no. 7123, pp. 106-110, 2007.

[6] H. Korkaya, A. Paulson, E. Charafe-Jauffret et al., "Regulation of mammary stem/progenitor cells by PTEN/Akt/ $\beta$-catenin signaling," PLoS Biology, vol. 7, no. 6, Article ID e1000121, 2009.

[7] S. J. Isakoff, "Triple-negative breast cancer: role of specific chemotherapy agents," Cancer Journal, vol. 16, no. 1, pp. 53-61, 2010.

[8] D. Subramaniam, S. Ramalingam, C. W. Houchen, and S. Anant, "Cancer stem cells: a novel paradigm for cancer prevention and treatment," Mini Reviews in Medicinal Chemistry, vol. 10, no. 5, pp. 359-371, 2010.

[9] W.-W. Chang, H. L. Chien, P. Lee et al., "Expression of Globo $\mathrm{H}$ and SSEA3 in breast cancer stem cells and the involvement of fucosyl transferases 1 and 2 in Globo $\mathrm{H}$ synthesis," Proceedings of the National Academy of Sciences of the United States of America, vol. 105, no. 33, pp. 11667-11672, 2008.

[10] W. W. Hwang-Verslues, W.-H. Kuo, P.-H. Chang et al., "Multiple lineages of human breast cancer stem/progenitor cells identified by profiling with stem cell markers," PloS one, vol. 4, no. 12, p. e8377, 2009.

[11] D. Hambardzumyan, M. Squartro, and E. C. Holland, "Radiation resistance and stem-like cells in brain tumors," Cancer Cell, vol. 10, no. 6, pp. 454-456, 2006.

[12] S. Liu, G. Dontu, I. D. Mantle et al., "Hedgehog signaling and Bmi-1 regulate self-renewal of normal and malignant human mammary stem cells," Cancer Research, vol. 66, no. 12, pp. 60636071, 2006.

[13] G. Dontu, K. W. Jackson, E. McNicholas, M. J. Kawamura, W. M. Abdallah, and M. S. Wicha, "Role of Notch signaling in cellfate determination of human mammary stem/progenitor cells," Breast Cancer Research, vol. 6, no. 6, pp. R605-R615, 2004. 
[14] M. J. Smalley and T. C. Dale, "Wnt signalling in mammalian development and cancer," Cancer and Metastasis Reviews, vol. 18, no. 2, pp. 215-230, 1999.

[15] V. V. Pogodina, "Elizaveta Nilolaevna Levkovich-75th birthday," Acta Virologica, vol. 19, no. 6, p. 509, 1975.

[16] F. C. Vasconcelos, G. B. Cavalcanti Jr., K. L. Silva et al., "Contrasting features of MDR phenotype in leukemias by using two fluorochromes: implications for clinical practice," Leukemia Research, vol. 31, no. 4, pp. 445-454, 2007.

[17] M. M. Gottesman, T. Fojo, and S. E. Bates, "Multidrug resistance in cancer: role of ATP-dependent transporters," Nature Reviews Cancer, vol. 2, no. 1, pp. 48-58, 2002.

[18] G.-S. Wang, "Medical uses of mylabris in ancient China and recent studies," Journal of Ethnopharmacology, vol. 26, no. 2, pp. 147-162, 1989.

[19] J. A. Sakoff, S. P. Ackland, M. L. Baldwin, M. A. Keane, and A. McCluskey, "Anticancer activity and protein phosphatase 1 and $2 \mathrm{~A}$ inhibition of a new generation of cantharidin analogues," Investigational New Drugs, vol. 20, no. 1, pp. 1-11, 2002.

[20] J. M. Einbinder, M. S. Parshley, R. A. Walzer, and S. L. Sanders, "The effect of cantharidin on epithelial cells in tissue culture," Journal of Investigative Dermatology, vol. 52, no. 3, pp. 291-303, 1969.

[21] A. McCluskey, M. C. Bowyer, E. Collins, A. T. R. Sim, J. A. Sakoff, and M. L. Baldwin, "Anhydride modified cantharidin analogues: synthesis, inhibition of protein phosphatases 1 and 2A and anticancer activity," Bioorganic and Medicinal Chemistry Letters, vol. 10, no. 15, pp. 1687-1690, 2000.

[22] T. Efferth, R. Rauh, S. Kahl et al., "Molecular modes of action of cantharidin in tumor cells," Biochemical Pharmacology, vol. 69, no. 5, pp. 811-818, 2005.

[23] D. J. Karras, S. E. Farrell, R. A. Harrigan, F. M. Henretig, and L. Gealt, "Poisoning from 'spanish fly' (cantharidin)," American Journal of Emergency Medicine, vol. 14, no. 5, pp. 478-483, 1996.

[24] Y.-Z. Fan, J.-Y. Fu, Z.-M. Zhao, and C.-Q. Chen, "Effect of norcantharidin on proliferation and invasion of human gallbladder carcinoma GBC-SD cells," World Journal of Gastroenterology, vol. 11, no. 16, pp. 2431-2437, 2005.

[25] Y.-N. Chen, C.-C. Cheng, J.-C. Chen, W. Tsauer, and S.-L. Hsu, "Norcantharidin-induced apoptosis is via the extracellular signal-regulated kinase and c-Jun- $\mathrm{NH}_{2}$-terminal kinase signaling pathways in human hepatoma HepG2 cells," British Journal of Pharmacology, vol. 140, no. 3, pp. 461-470, 2003.

[26] P.-Y. Yang, M.-F. Chen, Y.-H. Kao, D.-N. Hu, F.-R. Chang, and Y.-C. Wu, "Norcantharidin induces apoptosis of breast cancer cells: involvement of activities of mitogen activated protein kinases and signal transducers and activators of transcription," Toxicology in Vitro, vol. 25, no. 3, pp. 699-707, 2011.

[27] Y.-J. Chen, C.-D. Kuo, Y.-M. Tsai, C.-C. Yu, G.-S. Wang, and H.-F. Liao, "Norcantharidin induces anoikis through Jun-Nterminal kinase activation in CT26 colorectal cancer cells," AntiCancer Drugs, vol. 19, no. 1, pp. 55-64, 2008.

[28] Y. Y. Bei, X. Y. Chen, Y. Liu et al., "Novel norcantharidin-loaded liver targeting chitosan nanoparticles to enhance intestinal absorption," International Journal of Nanomedicine, vol. 7, pp. 1819-1827, 2012.

[29] S. Yi, J. Wass, P. Vincent, and H. Iland, "Inhibitory effect of norcantharidin on K562 human myeloid leukemia cells in vitro," Leukemia Research, vol. 15, no. 10, pp. 883-886, 1991.

[30] D. C. Dorn, C. A. Kou, K. J. Png, and M. A. S. Moore, “The effect of cantharidins on leukemic stem cells," International Journal of Cancer, vol. 124, no. 9, pp. 2186-2199, 2009.
[31] J. Zhang, Y. Tang, S. Li, C. Liao, and X. Guo, "Targeting of the B-lineage leukemia stem cells and their progeny with norcantharidin encapsulated liposomes modified with a novel CD19 monoclonal antibody 2E8 in vitro," Journal of Drug Targeting, vol. 18, no. 9, pp. 675-687, 2010.

[32] F. Cimmino, M. N. Scoppettuolo, M. Carotenuto et al., "Norcantharidin impairs medulloblastoma growth by inhibition of Wnt/ $\beta$-catenin signaling," Journal of Neuro-Oncology, vol. 106, no. 1, pp. 59-70, 2012.

[33] K. A. Chuang, C. H. Lieu, W. J. Tsai et al., "Evaluation of anti-Wnt/ $\beta$-catenin signaling agents by pGL4-TOP transfected stable cells with a luciferase reporter system," Brazilian Journal of Medical and Biological Research, vol. 43, no. 10, pp. 931-941, 2010.

[34] Y.-J. Chen, C.-J. Shieh, T.-H. Tsai et al., "Inhibitory effect of norcantharidin, a derivative compound from blister beetles, on tumor invasion and metastasis in CT28 colorectal adenocarcinoma cells," Anti-Cancer Drugs, vol. 16, no. 3, pp. 293-299, 2005.

[35] Y.-Z. Fan, Z.-M. Zhao, J.-Y. Fu, C.-Q. Chen, and W. Sun, "Norcantharidin inhibits growth of human gallbladder carcinoma xenografted tumors in nude mice by inducing apoptosis and blocking the cell cycle in vivo," Hepatobiliary and Pancreatic Diseases International, vol. 9, no. 4, pp. 414-422, 2010.

[36] Y.-Z. Fan, J.-Y. Fu, Z.-M. Zhao, and C.-Q. Chen, "Inhibitory effect of norcantharidin on the growth of human gallbladder carcinoma GBC-SD cells in vitro," Hepatobiliary and Pancreatic Diseases International, vol. 6, no. 1, pp. 72-80, 2007.

[37] Y.-C. Chen, S.-C. Chang, M.-H. Wu et al., "Norcantharidin reduced cyclins and cytokines production in human peripheral blood mononuclear cells," Life Sciences, vol. 84, no. 7-8, pp. 218226, 2009.

[38] Y.-J. Chen, Y.-M. Tsai, C.-D. Kuo, K.-L. Ku, H.-S. Shie, and H.-F. Liao, "Norcantharidin is a small-molecule synthetic compound with anti-angiogenesis effect," Life Sciences, vol. 85, no. 17-18, pp. 642-651, 2009.

[39] Y. J. Chen, C. D. Kuo, S. H. Chen et al., "Small-molecule synthetic compound norcantharidin reverses multi-drug resistance by regulating Sonic hedgehog signaling in human breast cancer cells," PLoS One, vol. 7, no. 5, Article ID e37006, 2012.

[40] Y.-J. Chen, W.-M. Chang, Y.-W. Liu et al., "A small-molecule metastasis inhibitor, norcantharidin, downregulates matrix metalloproteinase-9 expression by inhibiting Sp1 transcriptional activity in colorectal cancer cells," Chemico-Biological Interactions, vol. 181, no. 3, pp. 440-446, 2009.

[41] Y. Huang, Q. Liu, K. Liu, K. Yagasaki, and G. Zhang, "Suppression of growth of highly-metastatic human breast cancer cells by norcantharidin and its mechanisms of action," Cytotechnology, vol. 59, no. 3, pp. 201-208, 2009.

[42] Q. Liu, H. Duan, J. Luan, K. Yagasaki, and G. Zhang, "Effects of theanine on growth of human lung cancer and leukemia cells as well as migration and invasion of human lung cancer cells," Cytotechnology, vol. 59, no. 3, pp. 211-217, 2009.

[43] F. Chen, V. Castranova, and X. Shi, "New insights into the role of nuclear factor- $\kappa \mathrm{B}$ in cell growth regulation," American Journal of Pathology, vol. 159, no. 2, pp. 387-397, 2001.

[44] C.-B. Yeh, M.-J. Hsieh, Y.-H. Hsieh, M.-H. Chien, H.-L. Chiou, and S.-F. Yang, "Antimetastatic effects of norcantharidin on hepatocellular carcinoma by transcriptional inhibition of MMP-9 through modulation of NF-Kb activity," PLoS One, vol. 7, no. 2, Article ID e31055, 2012. 
[45] M. Guan, Q. L. Zhu, Y. Liu et al., "Uptake and transport of a novel anticancer drug-delivery system: lactosylnorcantharidin-associated N-trimethyl chitosan nanoparticles across intestinal Caco-2 cell monolayers," International Journal of Nanomedicine, vol. 7, pp. 1921-1930, 2012.

[46] S.-H. Kok, S.-J. Cheng, C.-Y. Hong et al., "Norcantharidininduced apoptosis in oral cancer cells is associated with an increase of proapoptotic to antiapoptotic protein ratio," Cancer Letters, vol. 217, no. 1, pp. 43-52, 2005.

[47] C.-H. Hsieh, H.-F. Liao, C.-D. Kuo et al., "Norcantharidin modulates development of dendritic cells and prolongs skin allograft survival," Transplantation, vol. 92, no. 8, pp. 848-857, 2011.

[48] Y. Li, Y. Sun, F. Liu et al., "Norcantharidin inhibits renal interstitial fibrosis by blocking the tubular epithelial-mesenchymal transition," PLoS One, vol. 8, no. 6, Article ID e66356, 2013.

[49] Y. Li, Q. Chen, F.-Y. Liu et al., "Norcantharidin attenuates tubulointerstitial fibrosis in rat models with diabetic nephropathy," Renal Failure, vol. 33, no. 2, Article ID 553305, pp. 233-241, 2011.

[50] M. S. Yan, S. Xiue, L. X. Wei, and X. H. Piao, “The preliminary observation on immunosuppressive effect of norcantharidin in mice," Immunopharmacology and Immunotoxicology, vol. 15, no. 1, pp. 79-85, 1993.

[51] G. Turashvili, J. Bouchal, G. Burkadze, and Z. Kolar, "Wnt signaling pathway in mammary gland development and carcinogenesis," Pathobiology, vol. 73, no. 5, pp. 213-223, 2007.

[52] T. Akiyama, "Wnt/ $\beta$-catenin signaling," Cytokine and Growth Factor Reviews, vol. 11, no. 4, pp. 273-282, 2000.

[53] P. Polakis, "Wnt signaling and cancer," Genes and Development, vol. 14, no. 15, pp. 1837-1851, 2000.

[54] W. J. Nelson and R. Nusse, "Convergence of Wnt, $\beta$-catenin, and cadherin pathways," Science, vol. 303, no. 5663, pp. 1483-1487, 2004.

[55] T.-C. He, A. B. Sparks, C. Rago et al., "Identification of c-MYC as a target of the APC pathway," Science, vol. 281, no. 5382, pp. 1509-1512, 1998.

[56] O. Tetsu and F. McCormick, " $\beta$-catenin regulates expression of cyclin D1 in colon carcinoma cells," Nature, vol. 398, no. 6726, pp. 422-426, 1999.

[57] B. Mann, M. Gelos, A. Siedow et al., "Target genes of $\beta$-catenin$\mathrm{T}$ cell-factor/lymphoid-enhancer-factor signaling in human colorectal carcinomas," Proceedings of the National Academy of Sciences of the United States of America, vol. 96, no. 4, pp. 1603$1608,1999$.

[58] H. Clevers, "Wnt/ $\beta$-catenin signaling in development and disease," Cell, vol. 127, no. 3, pp. 469-480, 2006.

[59] S.-Y. Lin, W. Xia, J. C. Wang et al., " $\beta$-catenin, a novel prognostic marker for breast cancer: its roles in cyclin D1 expression and cancer progression," Proceedings of the National Academy of Sciences of the United States of America, vol. 97, no. 8, pp. 42624266, 2000.

[60] S. Orsulic, O. Huber, H. Aberle, S. Arnold, and R. Kemler, "E-cadherin binding prevents $\beta$-catenin nuclear localization and $\beta$-catenin/LEF-1-mediated transactivation," Journal of Cell Science, vol. 112, part 8, pp. 1237-1245, 1999.

[61] A. Gritli-Linde, M. Bei, R. Maas, X. M. Zhang, A. Linde, and A. P. McMahon, "Shh signaling within the dental epithelium is necessary for cell proliferation, growth and polarization," Development, vol. 129, no. 23, pp. 5323-5337, 2002.

[62] L. Yang, G. Xie, Q. Fan, and J. Xie, "Activation of the hedgehogsignaling pathway in human cancer and the clinical implications," Oncogene, vol. 29, no. 4, pp. 469-481, 2010.
[63] S. Liu, G. Dontu, and M. S. Wicha, "Mammary stem cells, selfrenewal pathways, and carcinogenesis," Breast Cancer Research, vol. 7, no. 3, pp. 86-95, 2005.

[64] M. M. Cohen Jr., “The hedgehog signaling network," American Journal of Medical Genetics, vol. 123, no. 1, pp. 5-28, 2003.

[65] M. T. Lewis and J. M. Veltmaat, "Next top, the twilight zone: hedgehog network regulation of mammary gland development," Journal of Mammary Gland Biology and Neoplasia, vol. 9, no. 2, pp. 165-181, 2004.

[66] Y.-Z. Feng, T. Shiozawa, T. Miyamoto et al., "Overexpression of hedgehog signaling molecules and its involvement in the proliferation of endometrial carcinoma cells," Clinical Cancer Research, vol. 13, no. 5, pp. 1389-1398, 2007.

[67] M. P. Di Magliano and M. Hebrok, "Hedgehog signalling in cancer formation and maintenance," Nature Reviews Cancer, vol. 3, no. 12, pp. 903-911, 2003.

[68] V. Medina, M. B. Calvo, S. Díaz-Prado, and J. Espada, "Hedgehog signalling as a target in cancer stem cells," Clinical and Translational Oncology, vol. 11, no. 4, pp. 199-207, 2009.

[69] R. L. Carpenter and H. W. Lo, "Hedgehog pathway and GLI1 isoforms in human cancer," Discovery Medicine, vol. 13, no. 69, pp. 105-113, 2012.

[70] J. Huelsken and W. Birchmeier, "New aspects of Wnt signaling pathways in higher vertebrates," Current Opinion in Genetics and Development, vol. 11, no. 5, pp. 547-553, 2001.

[71] P. W. Ingham and A. P. McMahon, "Hedgehog signaling in animal development: paradigms and principles," Genes and Development, vol. 15, no. 23, pp. 3059-3087, 2001.

[72] M. A. Price and D. Kalderon, "Proteolysis of the Hedgehog signaling effector Cubitus interruptus requires phosphorylation by Glycogen Synthase Kinase 3 and Casein Kinase 1," Cell, vol. 108, no. 6, pp. 823-835, 2002.

[73] D. Kalderon, "Similarities between the Hedgehog and Wnt signaling pathways," Trends in Cell Biology, vol. 12, no. 11, pp. 523-531, 2002.

[74] S. Hoseong Yang, T. Andl, V. Grachtchouk et al., "Pathological responses to oncogenic Hedgehog signaling in skin are dependent on canonical Wnt/ $\beta$-catenin signaling," Nature Genetics, vol. 40, no. 9, pp. 1130-1135, 2008.

[75] M. Pap and G. M. Cooper, "Role of glycogen synthase kinase-3 in the phosphatidylinositol 3-kinase/Akt cell survival pathway," Journal of Biological Chemistry, vol. 273, no. 32, pp. 19929-19932, 1998.

[76] C. Yost, M. Torres, J. R. Miller, E. Huang, D. Kimelman, and R. T. Moon, "The axis-inducing activity, stability, and subcellular distribution of $\beta$-catenin is regulated in Xenopus embryos by glycogen synthase kinase 3," Genes and Development, vol. 10, no. 12, pp. 1443-1454, 1996.

[77] N. Sizemore, S. Leung, and G. R. Stark, "Activation of phosphatidylinositol 3-kinase in response to interleukin- 1 leads to phosphorylation and activation of the NF- $\kappa$ B p65/RelA subunit," Molecular and Cellular Biology, vol. 19, no. 7, pp. 47984805, 1999.

[78] B. B. Aggarwal, "Nuclear factor- $\kappa$ B: the enemy within," Cancer Cell, vol. 6, no. 3, pp. 203-208, 2004.

[79] N. A. Riobó, K. Lu, X. Ai, G. M. Haines, and C. P. Emerson Jr., "Phosphoinositide 3-kinase and Akt are essential for Sonic Hedgehog signaling," Proceedings of the National Academy of Sciences of the United States of America, vol. 103, no. 12, pp. 45054510, 2006. 
[80] A. M. Kenney, H. R. Widlund, and D. H. Rowitch, "Hedgehog and PI-3 kinase signaling converge on Nmycl to promote cell cycle progression in cerebellar neuronal precursors," Development, vol. 131, no. 1, pp. 217-228, 2004.

[81] J.-R. Fu, W.-L. Liu, J.-F. Zhou et al., "Sonic hedgehog protein promotes bone marrow-derived endothelial progenitor cell proliferation, migration and VEGF production via PI 3-kinase/Akt signaling pathways," Acta Pharmacologica Sinica, vol. 27, no. 6, pp. 685-693, 2006.

[82] S. Kanda, Y. Mochizuki, T. Suematsu, Y. Miyata, K. Nomata, and H. Kanetake, "Sonic hedgehog induces capillary morphogenesis by endothelial cells through phosphoinositide 3-kinase," Journal of Biological Chemistry, vol. 278, no. 10, pp. 8244-8249, 2003.

[83] H. Hahn, L. Wojnowski, K. Specht et al., "Patched target Igf2 is indispensable for the formation of medulloblastoma and rhabdomyosarcoma," Journal of Biological Chemistry, vol. 275, no. 37, pp. 28341-28344, 2000.

[84] G. Rao, C. A. Pedone, L. D. Valle, K. Reiss, E. C. Holland, and D. W. Fults, "Sonic hedgehog and insulin-like growth factor signaling synergize to induce medulloblastoma formation from nestin-expressing neural progenitors in mice," Oncogene, vol. 23, no. 36, pp. 6156-6162, 2004.

[85] Y. A. Yoo, M. H. Kang, H. J. Lee et al., "Sonic hedgehog pathway promotes metastasis and lymphangiogenesis via activation of Akt, EMT, and MMP-9 pathway in gastric cancer," Cancer Research, vol. 71, no. 22, pp. 7061-7070, 2011.

[86] Y.-P. Xia, R.-L. Dai, Y.-N. Li et al., "The protective effect of sonic hedgehog is mediated by the propidium iodide 3kinase/AKT/Bcl-2 pathway in cultured rat astrocytes under oxidative stress," Neuroscience, vol. 209, pp. 1-11, 2012.

[87] H. Nakashima, M. Nakamura, H. Yamaguchi et al., "Nuclear factor- $\kappa \mathrm{B}$ contributes to hedgehog signaling pathway activation through sonic hedgehog induction in pancreatic cancer," Cancer Research, vol. 66, no. 14, pp. 7041-7049, 2006.

[88] H. Kasperczyk, B. Baumann, K.-M. Debatin, and S. Fulda, "Characterization of sonic hedgehog as a novel NF- $\kappa \mathrm{B}$ target gene that promotes NF- $\kappa \mathrm{B}$-mediated apoptosis resistance and tumor growth in vivo," The FASEB Journal, vol. 23, no. 1, pp. 2133, 2009.

[89] Z. Wang, Y. Li, S. Banerjee, and F. H. Sarkar, "Emerging role of Notch in stem cells and cancer," Cancer Letters, vol. 279, no. 1, pp. 8-12, 2009.

[90] A. Wilson and F. Radtke, "Multiple functions of Notch signaling in self-renewing organs and cancer," FEBS Letters, vol. 580, no. 12, pp. 2860-2868, 2006.

[91] C. D. Peacock and D. N. Watkins, "Cancer stem cells and the ontogeny of lung cancer," Journal of Clinical Oncology, vol. 26, no. 17 , pp. 2883-2889, 2008.

[92] X. Fan and C. G. Eberhart, "Medulloblastoma stem cells," Journal of Clinical Oncology, vol. 26, no. 17, pp. 2821-2827, 2008.

[93] M. Kakarala and M. S. Wicha, "Implications of the cancer stem-cell hypothesis for breast cancer prevention and therapy," Journal of Clinical Oncology, vol. 26, no. 17, pp. 2813-2820, 2008.

[94] D. H. Scoville, T. Sato, X. C. He, and L. Li, "Current view: intestinal stem cells and signaling," Gastroenterology, vol. 134, no. 3, pp. 849-864, 2008.

[95] F. Oswald, S. Liptay, G. Adler, and R. M. Schmid, "NF- $\kappa$ B2 is a putative target gene of activated Notch-1 via RBP-J $\kappa$," Molecular and Cellular Biology, vol. 18, no. 4, pp. 2077-2088, 1998.

[96] M.-S. Jang, H. Miao, N. Carlesso et al., "Notch-1 regulates cell death independently of differentiation in murine erythroleukemia cells through multiple apoptosis and cell cycle pathways," Journal of Cellular Physiology, vol. 199, no. 3, pp. 418433, 2004.

[97] Z. Wang, S. Banerjee, Y. Li, K. M. W. Rahman, Y. Zhang, and F. H. Sarkar, "Down-regulation of Notch-1 inhibits invasion by inactivation of nuclear factor- $\kappa \mathrm{B}$, vascular endothelial growth factor, and matrix metalloproteinase- 9 in pancreatic cancer cells," Cancer Research, vol. 66, no. 5, pp. 2778-2784, 2006.

[98] P. Cheng, A. Zlobin, V. Volgina et al., "Notch-1 regulates NF- $\kappa \mathrm{B}$ activity in hemopoietic progenitor cells," Journal of Immunology, vol. 167, no. 8, pp. 4458-4467, 2001.

[99] C.-Y. Huang, Y.-C. Fong, C.-Y. Lee et al., "CCL5 increases lung cancer migration via PI3K, Akt and NF- $\kappa \mathrm{B}$ pathways," Biochemical Pharmacology, vol. 77, no. 5, pp. 794-803, 2009.

[100] Y.-Y. Wei, Y.-J. Chen, Y.-C. Hsiao, Y.-C. Huang, T.-H. Lai, and C.-H. Tang, "Osteoblasts-derived TGF- $\beta 1$ enhance motility and integrin upregulation through Akt, ERK, and NF- $\kappa$ Bdependent pathway in human breast cancer cells," Molecular Carcinogenesis, vol. 47, no. 7, pp. 526-537, 2008.

[101] N. H. Patel and M. L. Rothenberg, "Multidrug resistance in cancer chemotherapy," Investigational New Drugs, vol. 12, no. 1, pp. 1-13, 1994.

[102] S. V. Ambudkar, C. Kimchi-Sarfaty, Z. E. Sauna, and M. M. Gottesman, "P-glycoprotein: from genomics to mechanism," Oncogene, vol. 22, no. 47, pp. 7468-7485, 2003.

[103] J.-P. Marie, D.-C. Zhou, S. Gurbuxani, O. Legrand, and R. Zittoun, "MDR1/P-glycoprotein in haematological neoplasms," European Journal of Cancer, vol. 32, no. 6, pp. 1034-1038, 1996.

[104] S. P. C. Cole, G. Bhardwaj, J. H. Gerlach et al., "Overexpression of a transporter gene in a multidrug-resistant human lung cancer cell line," Science, vol. 258, no. 5088, pp. 1650-1654, 1992.

[105] G. D. Kruh and M. G. Belinsky, "The MRP family of drug efflux pumps," Oncogene, vol. 22, no. 47, pp. 7537-7552, 2003.

[106] M. Kitazono, T. Sumizawa, Y. Takebayashi et al., "Multidrug resistance and the lung resistance-related protein in human colon carcinoma SW-620 cells," Journal of the National Cancer Institute, vol. 91, no. 19, pp. 1647-1653, 1999.

[107] R. J. Scheper, H. J. Broxterman, G. L. Scheffer et al., "Overexpression of a $\mathrm{M}(\mathrm{r}) 110,000$ vesicular protein in non-Pglycoprotein-mediated multidrug resistance," Cancer Research, vol. 53, no. 7, pp. 1475-1479, 1993.

[108] O. Legrand, G. Simonin, A. Beauchamp-Nicoud, R. Zittoun, and J.-P. Marie, "Simultaneous activity of MRP1 and Pgp is correlated with in vitro resistance to daunorubicin and with in vivo resistance in adult acute myeloid leukemia," Blood, vol. 94, no. 3, pp. 1046-1056, 1999.

[109] L. Austin Doyle, W. Yang, L. V. Abruzzo et al., "A multidrug resistance transporter from human MCF-7 breast cancer cells," Proceedings of the National Academy of Sciences of the United States of America, vol. 95, no. 26, pp. 15665-15670, 1998.

[110] K. Miyake, L. Mickley, T. Litman et al., "Molecular cloning of cDNAs which are highly overexpressed in mitoxantroneresistant cells: demonstration of homology to ABC transport genes," Cancer Research, vol. 59, no. 1, pp. 8-13, 1999.

[111] L. A. Doyle and D. D. Ross, "Multidrug resistance mediated by the breast cancer resistance protein BCRP (ABCG2)," Oncogene, vol. 22, no. 47, pp. 7340-7358, 2003.

[112] S. K. Singh, C. Hawkins, I. D. Clarke et al., "Identification of human brain tumour initiating cells," Nature, vol. 432, no. 7015, pp. 396-401, 2004.

[113] L. Ricci-Vitiani, D. G. Lombardi, E. Pilozzi et al., "Identification and expansion of human colon-cancer-initiating cells," Nature, vol. 445, no. 7123, pp. 111-115, 2007. 
[114] T. Reya, S. J. Morrison, M. F. Clarke, and I. L. Weissman, "Stem cells, cancer, and cancer stem cells," Nature, vol. 414, no. 6859, pp. 105-111, 2001.

[115] P. Sanchez, A. M. Hernández, B. Stecca et al., "Inhibition of prostate cancer proliferation by interference with SONIC HEDGEHOG-GLI1 signaling," Proceedings of the National Academy of Sciences of the United States of America, vol. 101, no. 34, pp. 12561-12566, 2004.

[116] P. A. Beachy, S. S. Karhadkar, and D. M. Berman, "Tissue repair and stem cell renewal in carcinogenesis," Nature, vol. 432, no. 7015, pp. 324-331, 2004.

[117] S. Taş and O. Avci, "Induction of the differentiation and apoptosis of tumor cells in vivo with efficiency and selectivity," European Journal of Dermatology, vol. 14, no. 2, pp. 96-102, 2004.

[118] A. Molckovsky and L. L. Siu, "First-in-class, first-in-human phase I results of targeted agents: highlights of the 2008 American society of clinical oncology meeting," Journal of Hematology \& Oncology, vol. 1, p. 20, 2008.

[119] A. Wodarz and R. Nusse, "Mechanisms of Wnt signaling in development," Annual Review of Cell and Developmental Biology, vol. 14, pp. 59-88, 1998.

[120] P. J. Morin, "beta-catenin signaling and cancer," Bioessays, vol. 21, no. 12, pp. 1021-1030, 1999.

[121] R. T. Moon, B. Bowerman, M. Boutros, and N. Perrimon, "The promise and perils of Wnt signaling through $\beta$-catenin," Science, vol. 296, no. 5573, pp. 1644-1646, 2002.

[122] K. H. Emami, C. Nguyen, H. Ma et al., "A small molecule inhibitor of beta-catenin/CREB-binding protein transcription," Proceedings of the National Academy of Sciences of the United States of America, vol. 101, no. 34, pp. 12682-12687, 2004.

[123] M. Lepourcelet, Y.-N. P. Chen, D. S. France et al., "Smallmolecule antagonists of the oncogenic $\mathrm{Tcf} / \beta$-catenin protein complex," Cancer Cell, vol. 5, no. 1, pp. 91-102, 2004.

[124] M. Al-Hajj, M. S. Wicha, A. Benito-Hernandez, S. J. Morrison, and M. F. Clarke, "Prospective identification of tumorigenic breast cancer cells," Proceedings of the National Academy of Sciences of the United States of America, vol. 100, no. 7, pp. 39833988, 2003.

[125] G. P. Adams and L. M. Weiner, "Monoclonal antibody therapy of cancer," Nature Biotechnology, vol. 23, no. 9, pp. 1147-1157, 2005.

[126] B.-B. S. Zhou, H. Zhang, M. Damelin, K. G. Geles, J. C. Grindley, and P. B. Dirks, "Tumour-initiating cells: challenges and opportunities for anticancer drug discovery," Nature Reviews Drug Discovery, vol. 8, no. 10, pp. 806-823, 2009.

[127] A. Burges, P. Wimberger, C. Kümper et al., "Effective relief of malignant ascites in patients with advanced ovarian cancer by a trifunctional anti-EpCAM $\mathrm{x}$ anti-CD3 antibody: a phase I/II study," Clinical Cancer Research, vol. 13, no. 13, pp. 3899-3905, 2007.

[128] Y. F. Wang, C. J. Chang, C. P. Lin et al., "Expression of hedgehog signaling molecules as a prognostic indicator of oral squamous cell carcinoma," Head Neck, vol. 34, no. 11, pp. 1556-1561, 2012.

[129] W. K. Sinclair and R. A. Morton, "X-Ray and ultraviolet sensitivity of synchronized Chinese hamster cells at various stages of the cell cycle," Biophysical Journal, vol. 5, pp. 1-25, 1965.

[130] W. K. Sinclair and R. A. Morton, "X-ray sensitivity during the cell generation cycle of cultured Chinese hamster cells," Radiation Research, vol. 29, no. 3, pp. 450-474, 1966. 


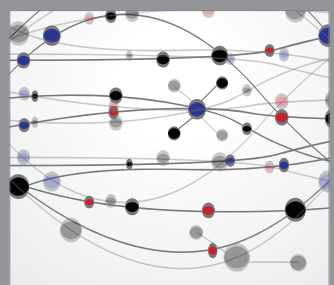

The Scientific World Journal
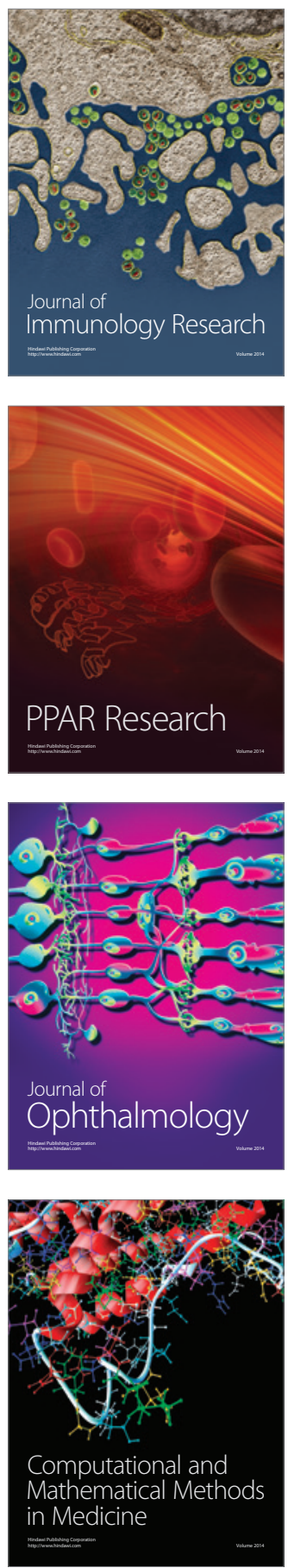

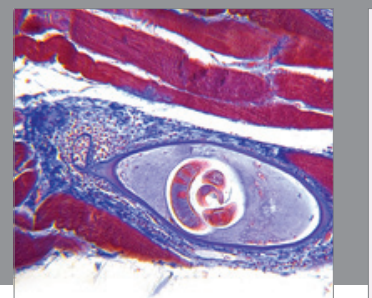

Gastroenterology

Research and Practice
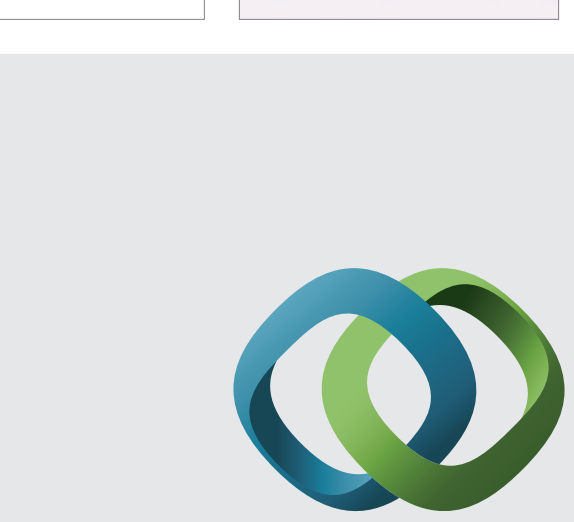

\section{Hindawi}

Submit your manuscripts at

http://www.hindawi.com
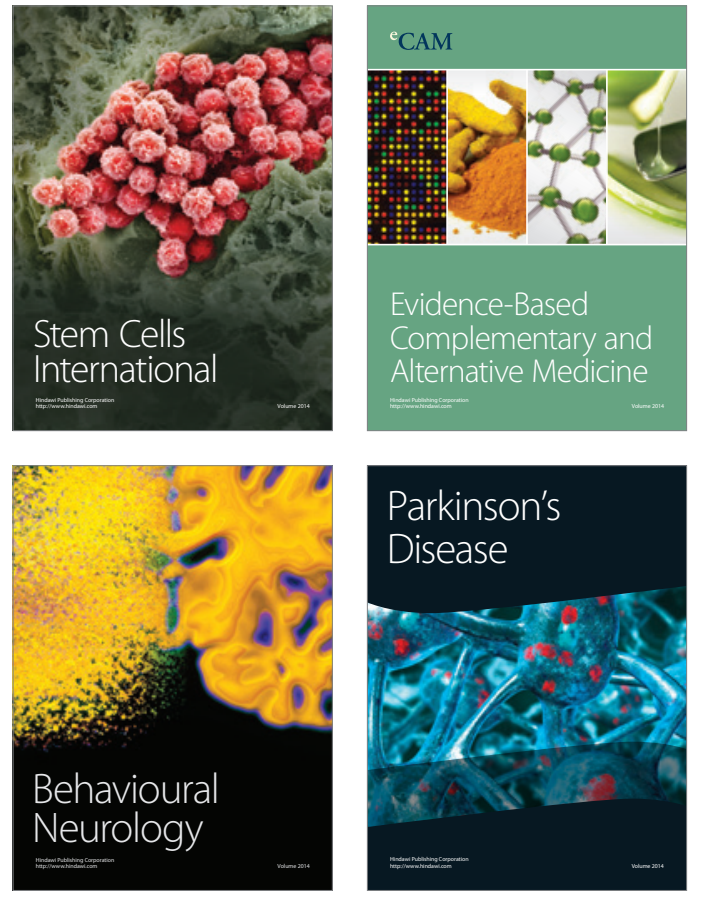
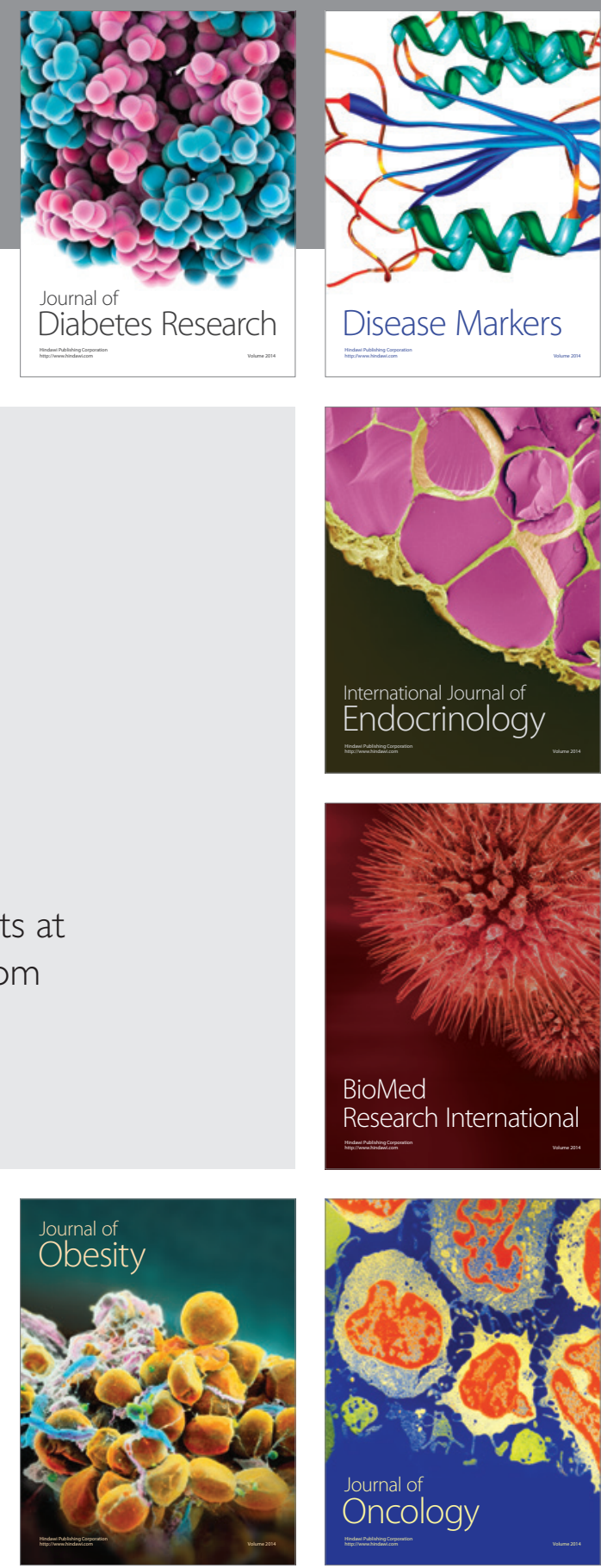

Disease Markers
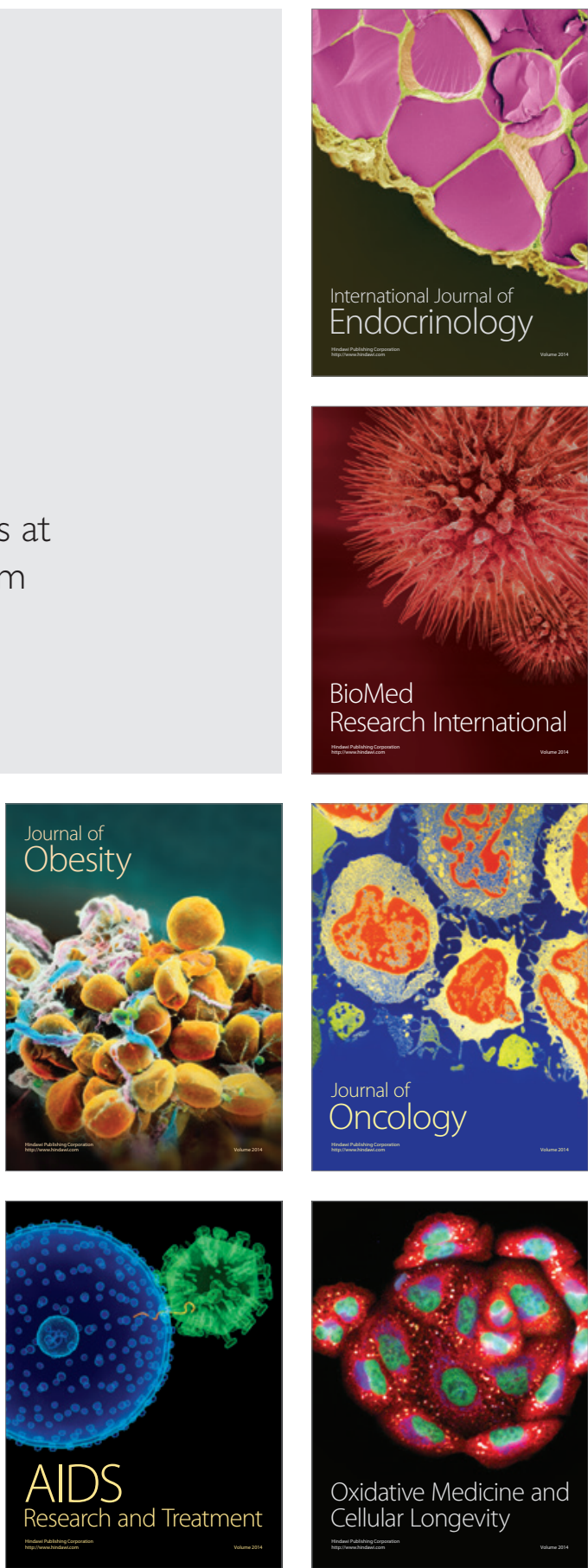